\title{
Corrigendum: Human somatic cell mutagenesis creates genetically tractable sarcomas
}

Sam D Molyneux, Paul D Waterhouse, Dawne Shelton, Yang W Shao, Christopher M Watling, Qing-Lian Tang, Isaac S Harris, Brendan C Dickson, Pirashaanthy Tharmapalan, Geir K Sandve, Xiaoyang Zhang, Swneke D Bailey, Hal Berman, Jay S Wunder, Zsuzsanna Iszvak, Mathieu Lupien, Tak W Mak \& Rama Khokha

Nat. Genet. 46, 964-972 (2014); published online 17 August 2014; corrected after print 16 October 2014

In the version of this article initially published, the name of author Zsuzsanna Izsvák was misspelled. The error has been corrected in the HTML and PDF versions of the article. 